\title{
Hydraulic Analysis of Ski Jump as An Energy Dissipator
}

\author{
Aishwarya Nale ${ }^{1}$, Sayali Thorat ${ }^{2}$, Yuvraj Vyavahare ${ }^{3}$, Shahrukh Shaikh ${ }^{4}$ \\ U.G. Student, Department of Civil Engineering, Sinhgad Institute of Technology and Science, Narhe, Pune, India ${ }^{1,2,3}$ \\ Assistant Professor, Department of Civil Engineering, Sinhgad Institute of Technology and Science, Narhe, Pune, \\ India $^{4}$
}

\begin{abstract}
One of the most effective and economical methods for the dissipation of hydraulic energy from flood waters is to project the flows into a free trajectory jet form to a location where the impact creates a plunge pool in the downstream river bed. This type of energy dissipation can be created by a ski-jump energy dissipator which has become an increasingly popular form of hydraulic energy dissipation for large dams in recent years due to its ability to safely convey high velocity flow in excess of $30 \mathrm{~m} / \mathrm{s}$ to the downstream river, however very limited definitive and comprehensive guidelines have been created. There is not only insufficient documentation for the conceptual and detailed design of ski-jump energy dissipators, there is also insufficient documentation for the dimensioning of the downstream plunge pools. Both are necessary to guarantee that the passage of major floods do not threaten the structural integrity of the permanent works.
\end{abstract}

Keywords: Hydraulic energy, dissipation, ski-jump, trajectory.

\section{INTRODUCTION}

\section{HYDRAULIC STRUCTURE:}

Hydraulic structures may be defined as a structure which allows the improvement and/or modification of flow features in water. The hydraulic assessment of such structure is necessary because such structure requires high strength since it is subjected by high velocities, large discharges as well as large hydrostatic pressures.

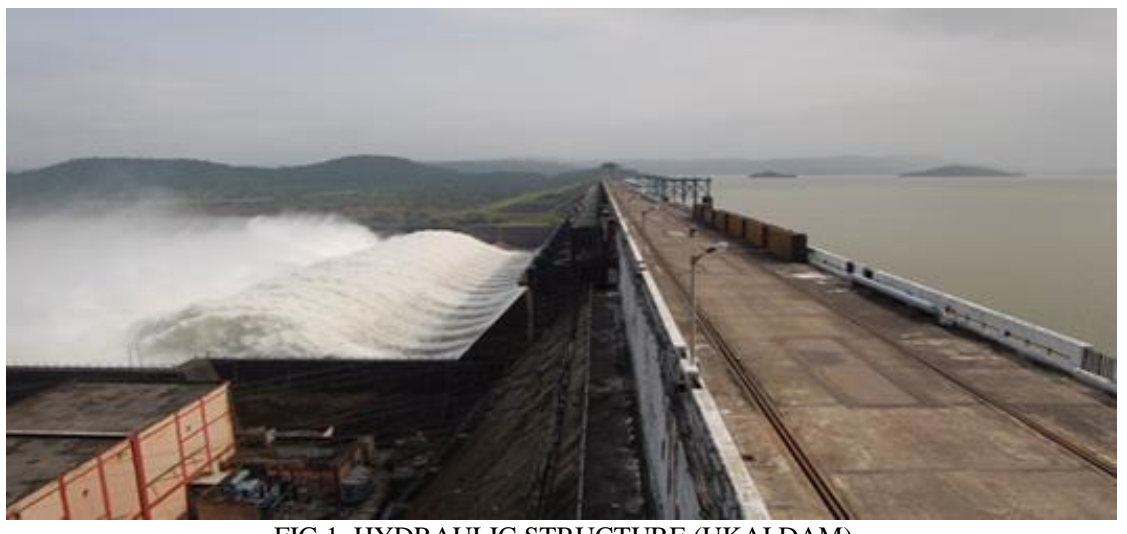

FIG.1. HYDRAULIC STRUCTURE (UKAI DAM)

The most essential civil engineering activity throughout all history is said to be dam engineering. Dams in their early existence were constructed with the primary function of a storage reservoir so that access to water was possible throughout the year including the dry season. Dams were envisioned to fulfill the arising need for irrigation at the time of organized agricultural development. There was a realization in the nineteenth century that the storage of water in dams and reservoirs played an essential role in society in relation to topics such as water supply, flood protection as well as energy generation.

Dams were built taller and wider with the advancement of dam engineering technologies and construction technique, and therefore discharges became larger and flow velocities became increasingly higher. Succeeding the Second World War the global development of large dams in excess of $100 \mathrm{~m}$ in height is remarkably illustrated by the dramatic increase in the total number of dams from 30 in 1945 to 500 by 1990 (Hager \& Boes, 2014).

Along with the advancements in dam engineering technology new problems such as energy dissipation and scour arose. One of the most effective and economical methods for the dissipation of hydraulic energy from taller dam is Ski-jump bucket energy dissipator. This research includes hydraulic testing of Ski-jump bucket energy dissipator with and without deflector. Ski-jump bucket energy dissipator become popular for large dams in recent years due to its ability to safely convey high velocity flow in excess of $20 \mathrm{~m} / \mathrm{s}$ to the downstream plunge pool. 


\section{CLASSIFICATION OF DAM:}

The three main categories of dam classification are:

I. Classification according to function

II. Classification according to hydraulic design and

III. Classification according to construction materials.

\section{Classification according to function:}

The relevant examples of dam which classified under this category are a Storage dam, Diversion dam and Detention dam.

\section{Classification by hydraulic design:}

In terms of hydraulic design dams may be classified as either overflow or non-overflow dams. Overflow dams are designed to convey flow over the crest and non-overflow dams are those designed so that overtopping does not exist.

\section{Classification by materials:}

The most common types of dam classified by materials are Earth fill dams, Rock fill dams and Concrete gravity dams.

\section{ENERGY DISSIPATING STRUCTURE:}

The water flowing over the spillway acquires a lot of kinetic energy by the time it reaches near the foot of the spillway. The arrangement made to dissipate this huge kinetic energy of water is known as energy dissipater. Energy dissipater is the structure constructed not only to protect the riverbed and banks from erosion, but also to ensure that the dam itself and adjoining structures are not undermined. The energy dissipators for spillways can be grouped under the following three categories i.e.:

I. Hydraulic jump stilling basins energy dissipator

II. Impact type energy dissipator

III. Buckets types of energy dissipator

\section{DEFLECTOR:}

The deflector always started at the beginning of the Ski-jump bucket and ended at its downstream crest. Deflectors are the element provided at the outlet to deflect the trajectory into an area of plunge pool where sound rock is present so that erosion will be less. Deflectors are also used:

1. To enhance jet dispersion,

2. To spread and

3. To elongate the jet trajectory.

Fig shows arrangement of deflector on ski-jump bucket used by Roman Juan in his study. Roman Juan investigated the main features of flip buckets including scale effects in hydraulic models, bucket pressure distribution, and nappe trajectories with and without the presence of deflectors.

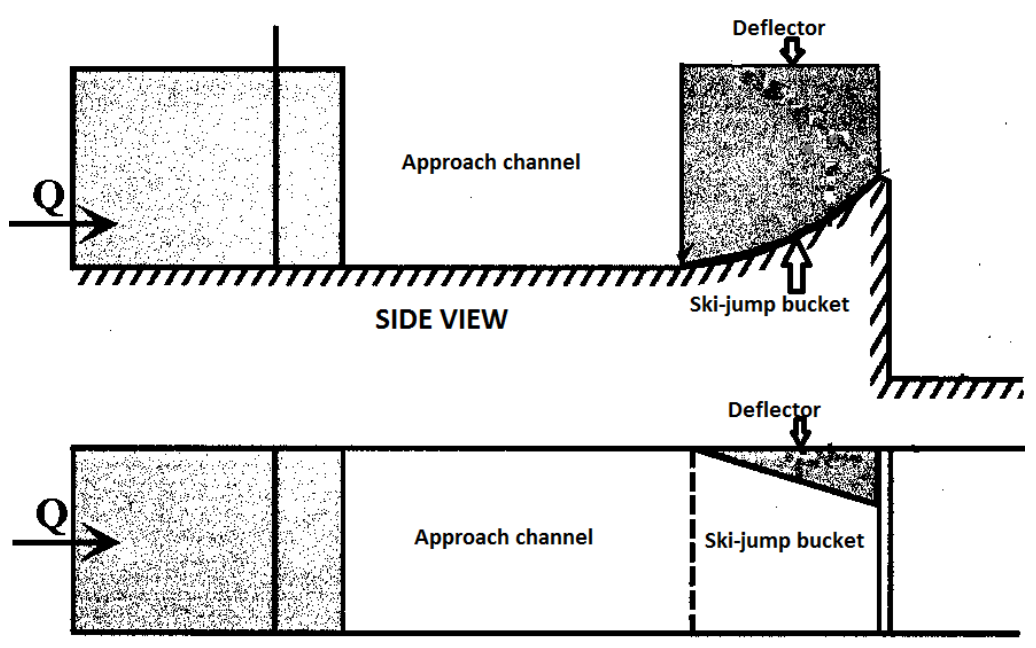

PLAN

FIG.2. SKI-JUMP BUCKET WITH DEFLECTOR (SHOWN IN ROMAN JUON 2000) 


\section{THE PRINCIPLE FEATURES OF HYDRAULIC DESIGN OF TRAJECTORY BUCKET}

Trajectory bucket type energy dissipator is considered more suitable when:

a) Tailwater depth is much lower than the sequent depth of hydraulic jump, thus preventing formation of the jump;

b) By locating at higher level, it may be used in case of higher tailwater depths also, if economy permits; and

c) Bed of the river channel downstream is composed of sound rock.

Provision of conventional hydraulic jump type apron or a roller bucket involves considerable excavation in hard strata which can be reduced appreciably. It is also necessary to have sufficient straight reach in the downstream of a ski-jump bucket. The flow coming down the spillway is thrown away in air from the toe of the structure to a considerable distance as a free discharging upturned jet which falls on the channel bed downstream. The hard bed can tolerate the spray from the jet and erosion by the plunging jet would not pose any significant problem for the safety of the structure. Thus, although there is very little energy dissipation within the bucket itself, possible channel bed erosion close to the downstream toe of the dam is minimized. In the trajectory bucket, only part of the energy is dissipated through interaction of the jet with the surrounding air. The remaining energy is imparted to the channel bed below. The channel bed should consist of sound, hard strata and should be free from laminations, joints and weak pockets to withstand the impact of jet.

The design of the trajectory bucket presupposes the formation of large craters or scour holes at the zone

of impact of the jet during the initial years of operation and, therefore, the design shall be restricted to sites where generally sound rock is available in the river bed. Special care shall be taken to strengthen weak pockets in the bed located in a length of about $15 \mathrm{~m}$ downstream of the bucket.

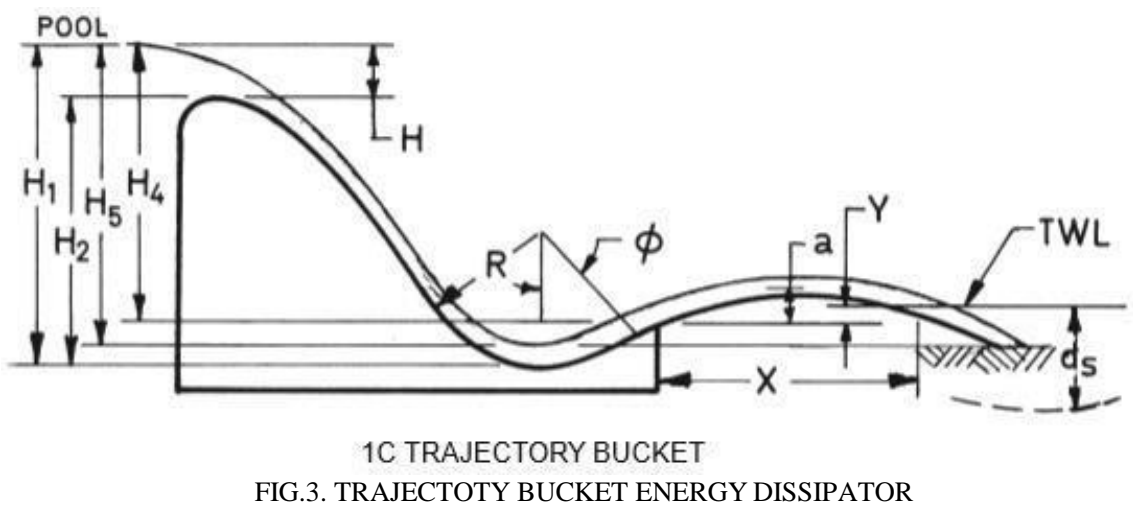

\section{HYDRAULIC MODEL}

A Hydraulic Model Of Ogee Spillway With A Ski-Jump Energy Dissipater Was Designed And Fabricated. The Hydraulic Model Study Was Conducted Inside The Fluid Mechanics Laboratory Department Of Civil Engineering, Aissms College Of Engineering Pune. The Hydraulic Model Will Be Fixed In Hydraulic Flume. The Laboratory Created A Controlled Environment Where No External Factors, Such As

Weather, Could Have An Influence On The Specific Tests Or The Data Acquired. Water Was Pumped To The Hydraulic Pump At The Inlet Of The Hydraulic Flume Where Constant Level Of Water Behind The Spillway Model Was Able To Maintain And Water Would Be Allowed To Overflow Above The Crest Controlled By

The Radial Gate Provided.

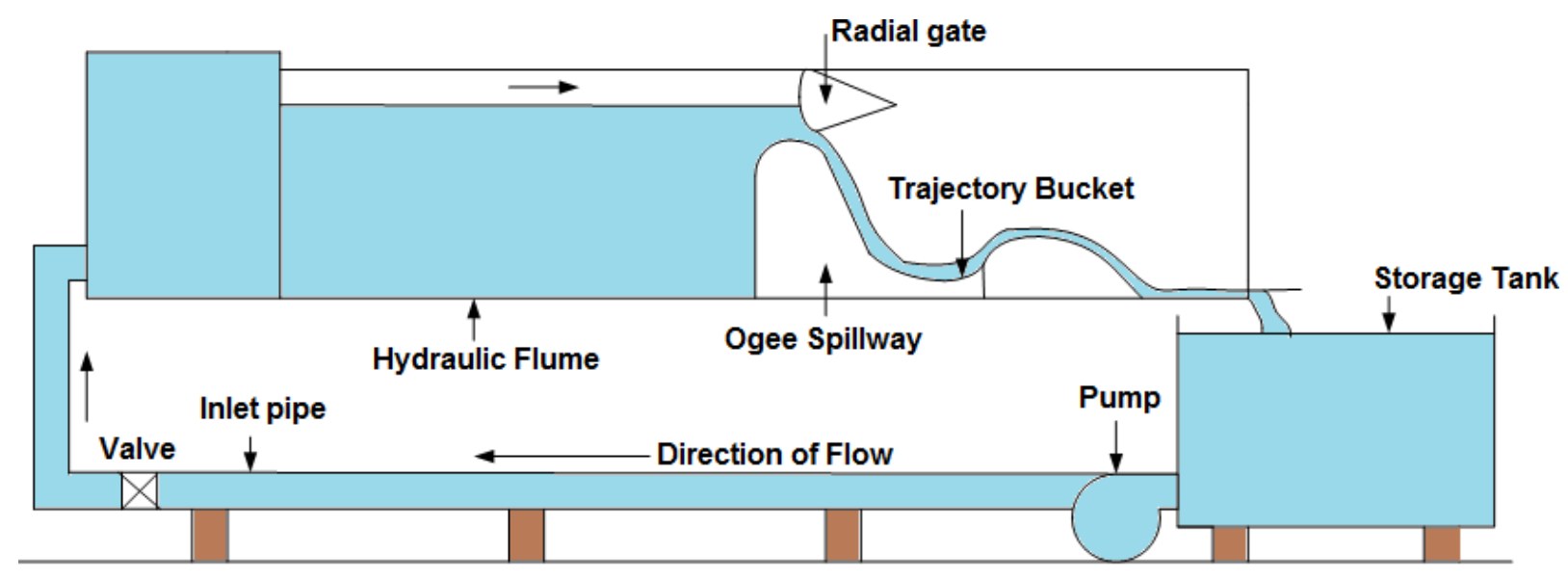

FIGURE 4. SCHTEMATIC DIAGRAM OF EXPERIMENTAL SETUP 
The ski-jump hydraulic model was designed with a scale of 1:100. This scale was chosen depending upon maximum discharge of hydraulic flume. The hydraulic model was designed to be geometrically similar to the prototype (Discharge $946.90 \mathrm{~m} 3 / \mathrm{s}$, width $30 \mathrm{~m}$ and height $21.2 \mathrm{~m}$ ) for Bhama Askhed dam spillway and therefore the flows act in agreement with the Froude's Law. Which is valid when the ratio of gravitational and inertial forces acting on a fluid particle are equal in the model and prototype therefore resulting in the following relationship between the prototype and model:

$$
\text { Frprototype }=\text { Frmodel }
$$

\section{CONCLUSION}

In this project, 1:100 physical model of a ski-jump deflector bucket was hydraulically tested where two different ski- jump bucket designs with ten flow conditions were analysed to determine a design that maximizes energy dissipation and minimizes trajectory throw length and width of impact at tail water pool level. In order to quantify the energy dissipation of the different flip bucket designs, a combined analysis of the trajectory profiles, impact width, plunge pool depth, depth at lip of bucket were conducted.

This experiment concludes that:

The maximum height of the trajectory for deflector bucket was found to be always greater than the conventional skijump bucket for all flow conditions of discharge.

The lower trajectory distance and middle trajectory distance were less for deflector bucket as compared to the conventional ski-jump bucket.

The upper trajectory distance for deflector bucket was always greater than the conventional ski-jump for all flow conditions.

\section{REFERENCES}

[1] Shangtuo, Qian.,Jianhua, Wu., and Fei, Ma. (2016). "Hydraulic Performance of Ski-Jump-Step Energy Dissipater.” J. Hydraul. Eng., 05016004:1-7.

[2] Jian-hua, WU.,Zhun XU., and Li, YAO. (2016). "Ski-jump trajectory based on take-off velocity.” J. Hydrodynamics., 28(1):166-169.

[3] Pfister, M., Hager, W. H., and Boes, R. M. (2014). "Trajectories and air flow features of ski jump-generated jets.” J. Hydraul. Res., 52(3), 336-346.

[4] Schmocker, L., Pfister, M., Hager, W. H., and Minor, H. E. (2008). “Aeration characteristics of ski jump jets.” J. Hydraul. Eng., 134(1): 90-97.

[5] Steiner, R., Hager, W. H., and Minor, H. E. (2008). “Deflector ski jump hydraulics.” J. Hydraul. Eng., 134(5): 562- 571.

[6] Heller, V., Hager, W. H., and Minor, H.E. (2005). "Ski jump hydraulics." J. Hydraul. Eng., 131(5): 347-355.

[7] V. S. Ramarao., K. T. More., M. R. Bhajantri., and V. V. Bhosekar.(2016) "Assessment of Scour Downstream of Spillway with Submerged Ski Jump Buckets."21st International Conference on Hydraulics, Water Resources and Coastal Engineering.

[8] B .S. Sundarlal., Dr. M.R. Bhajantri., Dr.(Mrs.) V.V.Bhosekar., B.M.Simpiger., Amol. H. Gaikwad. (2016) "Review of critical issues in the design of spillway and energy dissipator, mangdechhu hydroelectric project, Bhutan." 21 st International Conference on Hydraulics, Water Resources and Coastal Engineering.

[9] S. K. Mujumdar., P. L. Patel. (2001) "Model study of ski-jump type of energy dissipator.” International Conference on Hydraulics, Water Resources and Coastal Engineering.

[10] Jill, Lucas., Willi, H. Hager., and Robert, M. Boes. (2013). "Deflector Effect on Chute Flow.”J. Hydraul. Eng., 139(4): 444-449.

[11] Juon, R., and Hager, W. H. (2000). "Flip bucket without and with deflectors." J. Hydraul. Eng., 126(11): 837-845.

[12] Bureau of Indian standards. "Criteria for hydraulic design of bucket type of energy dissipators." IS: $7365: 2010$ (Second revision). 